\title{
Intestinal Colonization with Tropheryma whipplei-Clinical and Immunological Implications for HIV Positive Adults in Ghana
}

\author{
Kirsten Alexandra Eberhardt ${ }^{1,2, * \mathbb{D}}$, Fred Stephen Sarfo ${ }^{3,4}{ }^{\text {, Eva-Maria Klupp }}{ }^{5}$, Albert Dompreh ${ }^{6}$, \\ Veronica Di Cristanziano ${ }^{7}\left(\mathbb{D}\right.$, Edmund Osei Kuffour ${ }^{8}$, Richard Boateng ${ }^{6}$, Betty Norman ${ }^{3,4}$ (D), \\ Richard Odame Phillips ${ }^{3,4,9}$, Martin Aepfelbacher ${ }^{5}$ and Torsten Feldt ${ }^{10}$
}

check for updates

Citation: Eberhardt, K.A.; Sarfo, F.S.; Klupp, E.-M.; Dompreh, A.;

Di Cristanziano, V.; Osei Kuffour, E.; Boateng, R.; Norman, B.;

Phillips, R.O.; Aepfelbacher, M.; et al. Intestinal Colonization with

Tropheryma whipplei-Clinical and Immunological Implications for HIV Positive Adults in Ghana.

Microorganisms 2021, 9, 1781.

https://doi.org/10.3390/

microorganisms 9081781

Academic Editor: Anna Beltrame

Received: 1 August 2021

Accepted: 18 August 2021

Published: 22 August 2021

Publisher's Note: MDPI stays neutral with regard to jurisdictional claims in published maps and institutional affiliations.

Copyright: (c) 2021 by the authors. Licensee MDPI, Basel, Switzerland. This article is an open access article distributed under the terms and conditions of the Creative Commons Attribution (CC BY) license (https:/ / creativecommons.org/licenses/by/ $4.0 /)$.
1 Department of Tropical Medicine, Bernhard Nocht Institute for Tropical Medicine \& I. Department of Medicine, University Medical Center Hamburg-Eppendorf, 20359 Hamburg, Germany

2 Institute for Transfusion Medicine, University Medical Center Hamburg-Eppendorf, 20251 Hamburg, Germany

3 Department of Medicine, Kwame Nkrumah University of Science and Technology, 00233 Kumasi, Ghana; stephensarfo78@gmail.com (F.S.S.); branorman@yahoo.com (B.N.); phillips@kccr.de (R.O.P.)

4 Department of Medicine, Komfo Anokye Teaching Hospital, 00233 Kumasi, Ghana

5 Institute of Medical Microbiology, Virology and Hygiene, University Medical Centre Hamburg-Eppendorf, 20251 Hamburg, Germany; e.klupp@uke.de (E.-M.K.); maepfelbacher@uke.de (M.A.)

6 Department of Clinical Microbiology, Komfo Anokye Teaching Hospital, 00233 Kumasi, Ghana; adompreh@gmail.com (A.D.); richardboateng166@gmail.com (R.B.)

7 Institute of Virology, Faculty of Medicine and University Hospital Cologne, University of Cologne, 50935 Cologne, Germany; veronica.di-cristanziano@uk-koeln.de

8 Laboratory of Retrovirology, The Rockefeller University, New York, NY 10065, USA; eosei@rockefeller.edu

9 Kumasi Center for Collaborative Research in Tropical Medicine, 00233 Kumasi, Ghana

10 Clinic of Gastroenterology, Hepatology and Infectious Diseases, University Hospital Düsseldorf, 40225 Düsseldorf, Germany; torsten.feldt@med.uni-duesseldorf.de

* Correspondence: k.eberhardt@bnitm.de; Tel.: +49-40-428-180

Abstract: Background: Recent studies demonstrated higher prevalence rates of Tropheryma whipplei (T. whipplei) in HIV positive than in HIV negative subjects. However, associations with the immune status in HIV positive participants were conflicting. Methods: For this cross-sectional study, stool samples of 906 HIV positive and 98 HIV negative individuals in Ghana were tested for T. whipplei. Additionally, sociodemographic parameters, clinical symptoms, medical drug intake, and laboratory parameters were assessed. Results: The prevalence of T. whipplei was 5.85\% in HIV positive and $2.04 \%$ in HIV negative participants. Within the group of HIV positive participants, the prevalence reached $7.18 \%$ in patients without co-trimoxazole prophylaxis, $10.26 \%$ in subjects with ART intake, and $12.31 \%$ in obese participants. Frequencies of clinical symptoms were not found to be higher in HIV positive T. whipplei carriers compared to T. whipplei negative participants. Markers of immune activation were lower in patients colonized with T. whipplei. Multivariate regression models demonstrated an independent relationship of a high CD4+ T cell count, a low HIV-1 viral load, and an obese body weight with the presence of T. whipplei. Conclusions: Among HIV positive individuals, T. whipplei colonization was associated with a better immune status but not with clinical consequences. Our data suggest that the withdrawal of co-trimoxazole chemoprophylaxis among people living with HIV on stable cART regimen may inadvertently increase the propensity towards colonization with T. whipplei.

Keywords: Whipple's disease; enteric infections; Sub-Sahara; Africa; epidemiology

\section{Introduction}

Tropheryma whipplei (T. whipplei) is the causative agent of Whipple's disease, a rare systemic infectious disease. Classic Whipple's disease typically involves the gastrointestinal tract and is associated with diverse intra- and extra-intestinal manifestations [1-4]. 
However, the detection of T. whipplei in asymptomatic carriers indicates that colonization is common and that only a minority of infected individuals ultimately develop Whipple's disease upon exposure to this soil microbe $[5,6]$.

The prevalence of T. whipplei varies considerably across studies, subjects and geographic regions. Detection rates observed in resource-limited settings are generally higher than in more developed countries [7-10]. Furthermore, children are at higher risk of being colonized than adults $[6,8,11]$. Differences between sample specimens and applied PCR assays might also contribute to observed variations [12].

Symptomatic cases of Whipple's diseases are commonly treated with short-term parenteral ceftriaxone or penicillin, followed by oral co-trimoxazole for one year [1]. At the same time, daily co-trimoxazole is recommended for African adults living with HIV, irrespective of antiretroviral treatment, immune status, or disease change [13]. As T. whipplei is susceptible to co-trimoxazole, potential long-term prophylaxis has to be accounted for when interpreting prevalence rates in HIV positive African populations.

Studies from Europe and the US reported higher prevalence and abundance rates of T. whipplei in people living with HIV (PLHIV) than in HIV negative subjects [14-16]. Further, Lozupone et al. observed a decline of this microbe in respiratory samples after initiation of antiretroviral therapy (ART), whereas a longitudinal study in healthy subjects without any antibiotic or antiviral treatment demonstrated a persistence of T. whipplei over time [17]. A study from Spain found increased prevalence rates in HIV positive subjects with metabolic syndrome (MetS) compared to PLHIV without MetS [15]. Since long-term antiretroviral treatment increases the chance of developing MetS, these results contrast those from Lozupone et al. to a certain degree [18].

By investigating the prevalence of T. whipplei in stool samples of PLHIV in Sub-Saharan Africa, we aim to contribute to the understanding of this pathogen and its clinical relevance in immunocompromised subjects with varying immune status and anti-retroviral and antibiotic treatment experiences.

\section{Materials and Methods}

\subsection{Study Setting}

This cross-sectional study is part of a larger study investigating the prevalence of Helicobacter pylori (H. pylori) and other gastrointestinal pathogens in HIV positive and negative adults in the Ashanti Region, Ghana [19-21]. Between November 2011 and November 2012, consecutive HIV positive patients presenting to the HIV outpatient department of the Komfo Anokye Teaching Hospital, and HIV negative blood donors, were offered participation in the study. All participants gave a written informed consent prior to enrolment. The study was approved by the appropriate ethics committees in Ghana (CHRPE/AP/12/11) and Germany (PV3771). Reporting followed the STROBE (Strengthening the Reporting of Observational Studies in Epidemiology Statement) recommendations (Supplementary File).

\subsection{Data Collection and Laboratory Methods}

Trained study personnel collected demographic and clinical data using a standardized questionnaire. Blood samples were collected, and the analysis of CD4+ T cell count was performed in Ghana using a FACSCalibur flow cytometer (Becton Dickinson, Mountain View, CA, USA). HIV-1 viral load was measured using the Real-Time HIV-1 PCR system (Abbott Diagnostics, Wiesbaden, Germany).

Peripheral blood mononuclear cells (PBMCs) were isolated by centrifugation of heparinized venous blood on a Ficoll/Hypaque (Biocoll Seperating Solution, Biochrom AG, Berlin, Germany) density gradient. Cells were washed in phosphate-buffered saline and resuspended in Roswell Park Memorial Institute 1640 medium (both Gibco Invitrogen, Carlsbad, CA, USA) supplemented with heat-inactivated fetal calf serum (Biochrom AG, Berlin, Germany). PBMCs were cryopreserved and shipped to Germany on liquid nitrogen. Cell surface markers for immune activation were stained as described in our previous 
work [22]. Flow cytometric data were acquired using the LSRII flow cytometer (BD Biosciences, Heidelberg, Germany) and analyzed using FlowJo version 9.6.2 (Tree Star, San Carlos, CA, USA).

Aliquots of native stool samples were freshly frozen and stored at $-80^{\circ} \mathrm{C}$ before being transported to Germany on dry ice. Nucleic acids were extracted applying the QiaAMP DNA Stool Mini kit (Qiagen, Hilden, Germany). Real-time PCR for T. whipplei was performed as previously published [23,24]. Briefly, primer and probe for target 1: TW27-F TGTTTTGTACTGCTTGTAACAGGATCT; TW182-R TCCTGCTCTATCCCTCCTATCAT, TX27182P, FAMAGAGATACATTTGTGTTAGTTGTTACA-BHQ-1; and for target 2: TW13-F TGAGTGATGGTAGTCTGAGAGATATGT; TW163-R TCCATAACAAAGACAACAACCAATC, TW13163P, FAMAGAAGAAGATGTTACGGGTTG-BHQ1 were used. Both PCRs (TW27-182 and TW13-163) were performed in a 25- $\mu \mathrm{L}$ total volume using Roche LightCycler 480 II (Roche, Mannheim, Germany), the Quantifast Pathogen PCR Kit (Qiagen) and $5 \mu \mathrm{L}$ of nucleic acid eluate. Only samples positive for both targets (TW27-182 and TW13-163, both with $\mathrm{Ct}$ values $\leq 37$ ) were defined as $T$. whipplei positive.

\subsection{Statistical Analyses}

Continuous variables were expressed as median (interquartile range, IQR) or mean \pm standard deviation (SD) and compared using the Wilcoxon rank sum test or the unpaired Student's t-test. Categorical variables were compared using either the $\chi^{2}$ test or the Fisher exact test, as appropriate. Potential associations of independent parameters with the T. whipplei status were assessed by applying multivariate logistic regression models adjusting for demographic and treatment-related parameters using the 'forestmodel' package in R (version 4.0.5, R Foundation for Statistical Computing, Vienna, Austria). To account for moderation, models were additionally run with included interaction terms. Only available data were considered for analysis without application of imputation methods in case of missing data points. Two-sided $p$-values were presented, and an $\alpha$ of 0.05 was determined as the cutoff for significance.

\section{Results}

A total of 1095 HIV positive individuals and 107 HIV negative blood donors were recruited for this study. Stool samples for T. whipplei testing were available for $906(82.7 \%)$ HIV positive and $98(91.6 \%)$ HIV negative individuals. The prevalence of T. whipplei was $5.85 \%(n=53)$ in HIV positive participants and $2.04 \%(n=2, p=0.158)$ in HIV negative participants (Figure 1). Within the group of HIV positive participants, the prevalence varied depending on subgrouping and reached $7.18 \%$ in patients without co-trimoxazole prophylaxis (vs. $3.21 \%$ in those with co-trimoxazole intake, $p=0.021$ ), $10.26 \%$ in subjects with ART intake (vs. $1.89 \%$ in ART-naïve patients, $p<0.001$ ) and $12.31 \%$ in obese HIV positive participants (vs. $5.28 \%$ in non-obese subjects, $p=0.046$ ).

HIV positive participants with present or absent $T$. whipplei were not different with regards to age, sex, or any of the recorded socioeconomic factors (Table 1). Furthermore, frequencies of clinical symptoms were not found to be higher in HIV positive T. whipplei carriers compared to $T$. whipplei negative participants.

HIV positive participants who were co-infected with T. whipplei were more frequently receiving antiretroviral therapy and less common co-trimoxazole as antibiotic prophylaxis $(83.02 \%$, vs. $45.19 \%, p<0.001$, and $16.98 \%$ vs. $32.26 \%, p=0.030$, Figure 2$)$. Subsequently, a smaller proportion of $T$. whipplei carriers had viral loads above 500 copies $/ \mathrm{mL}$ or CD4+ T cell counts lower than 200 cells $/ \mu$ L detected $(31.25 \%$ vs. $60.00 \%, p<0.001$, and $9.80 \%$ vs. $26.36 \%, p=0.013$, respectively). Furthermore, T. whipplei positive individuals presented more than twice as often with an obese body weight (Body mass index [BMI] $>30 \mathrm{~kg} / \mathrm{m}^{2}$ ) than those tested negative for T. whipplei $(15.69 \%$ vs. $6.88 \%, p=0.040)$. 


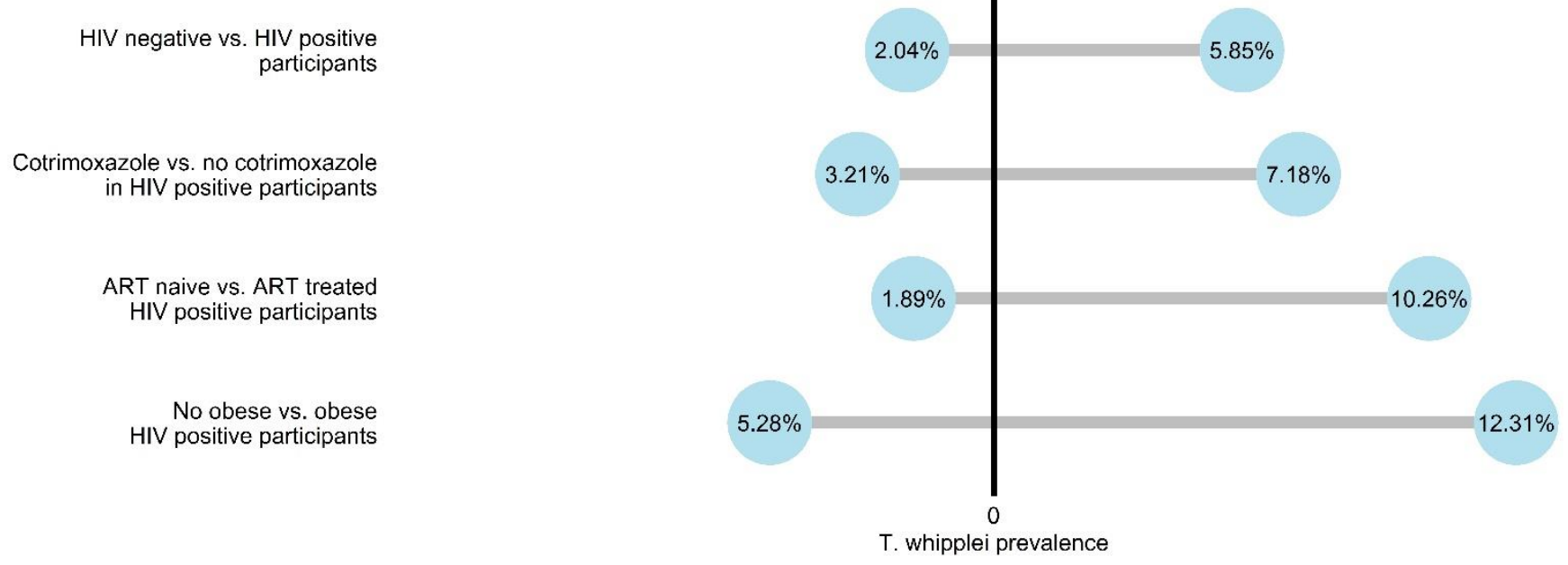

Figure 1. Prevalence of T. whipplei according to cohort characteristics.

Table 1. Demographical and socioeconomic parameters, and clinical symptoms in HIV infected individuals according to T. whipplei status.

\begin{tabular}{|c|c|c|c|c|}
\hline & Variable & $\begin{array}{c}\text { HIV Positive } \\
\text { T. whipplei } \\
\text { Negative, } \\
n=853(94.15 \%)\end{array}$ & $\begin{array}{c}\text { HIV Positive } \\
\text { T. whipplei } \\
\text { Positive, } \\
n=53(5.85 \%)\end{array}$ & $p$-Value \\
\hline \multirow{2}{*}{ Demographics } & Age in years $\pm S D$ & $40.5 \pm 9.5$ & $38.5 \pm 7.9$ & 0.127 \\
\hline & Female, n (\%) & $643(75.38)$ & $42(79.25)$ & 0.638 \\
\hline \multirow{5}{*}{$\begin{array}{l}\text { Socioeconomic } \\
\text { parameters }\end{array}$} & Access to tap water, n (\%) & 449 (52.64) & $29(54.72)$ & 0.879 \\
\hline & Electricity in household, $\mathrm{n}(\%)$ & $792(92.85)$ & $49(92.45)$ & 0.787 \\
\hline & Television in household, $\mathrm{n}(\%)$ & $689(80.77)$ & $42(79.25)$ & 0.925 \\
\hline & Refrigerator in household, n (\%) & $603(70.69)$ & $34(64.15)$ & 0.392 \\
\hline & Owning a car, $\mathrm{n}(\%)$ & $80(9.38)$ & $4(7.55)$ & 0.810 \\
\hline \multirow{5}{*}{$\begin{array}{l}\text { Clinical symptoms } \\
\text { during the last } \\
\text { six months }\end{array}$} & Any acute or chronic cough, $\mathrm{n}(\%)$ & $100(11.74)$ & $3(5.66)$ & 0.262 \\
\hline & $\begin{array}{l}\text { Any acute or chronic gastrointestinal } \\
\text { symptoms, } \mathrm{n}(\%)\end{array}$ & $105(12.32)$ & $4(7.55)$ & 0.387 \\
\hline & Any acute or chronic fever, n (\%) & $84(9.86)$ & $2(3.77)$ & 0.222 \\
\hline & Weigh loss during last six months, $\mathrm{n}(\%)$ & $201(23.59)$ & $6(11.32)$ & 0.058 \\
\hline & $\begin{array}{c}\text { Any acute or chronic symptoms of the } \\
\text { above, } \mathrm{n}(\%)\end{array}$ & $265(31.10)$ & $10(18.87)$ & 0.084 \\
\hline
\end{tabular}

SD—standard deviation.

In addition to lower HIV viral loads and higher CD4+ T cell counts (1.6 [0.0-3.3 IQR] vs. 4.0 [1.6-5.3 IQR], $p<0.001$, and 525.0 [371.0-654.5 IQR] vs. 396.0 [184.0-632.5 IQR], $p=0.007$, respectively), HIV positive individuals with $T$. whipplei carriage had a higher CD4+/CD8+ T cell ratio (0.5 [0.4-0.8 IQR] vs. 0.4 [0.2-0.7 IQR], $p=0.020)$ and a lower expression of HLA-DR+CD38+ on CD4+ T lymphocytes (11.2\% [7.3-19.7 IQR] vs. $18.4 \%$ [10.4-32.8 IQR], $p=0.009)$ and CD8+ T lymphocytes (29.1\% [22.7-40.5 IQR] vs. $42.3 \%$ [27.5$55.7 \mathrm{IQR}], p=0.006$ ), as markers of decreased immune activation (Table 2). Furthermore, individuals with $T$. whipplei had a higher proportion of CD57+, as a marker for terminal differentiation on CD8+ T lymphocytes (54.6\% [44.8-68.5 IQR] vs. 49.0\% [38.9-60.3 IQR], $p=0.049$ ). 


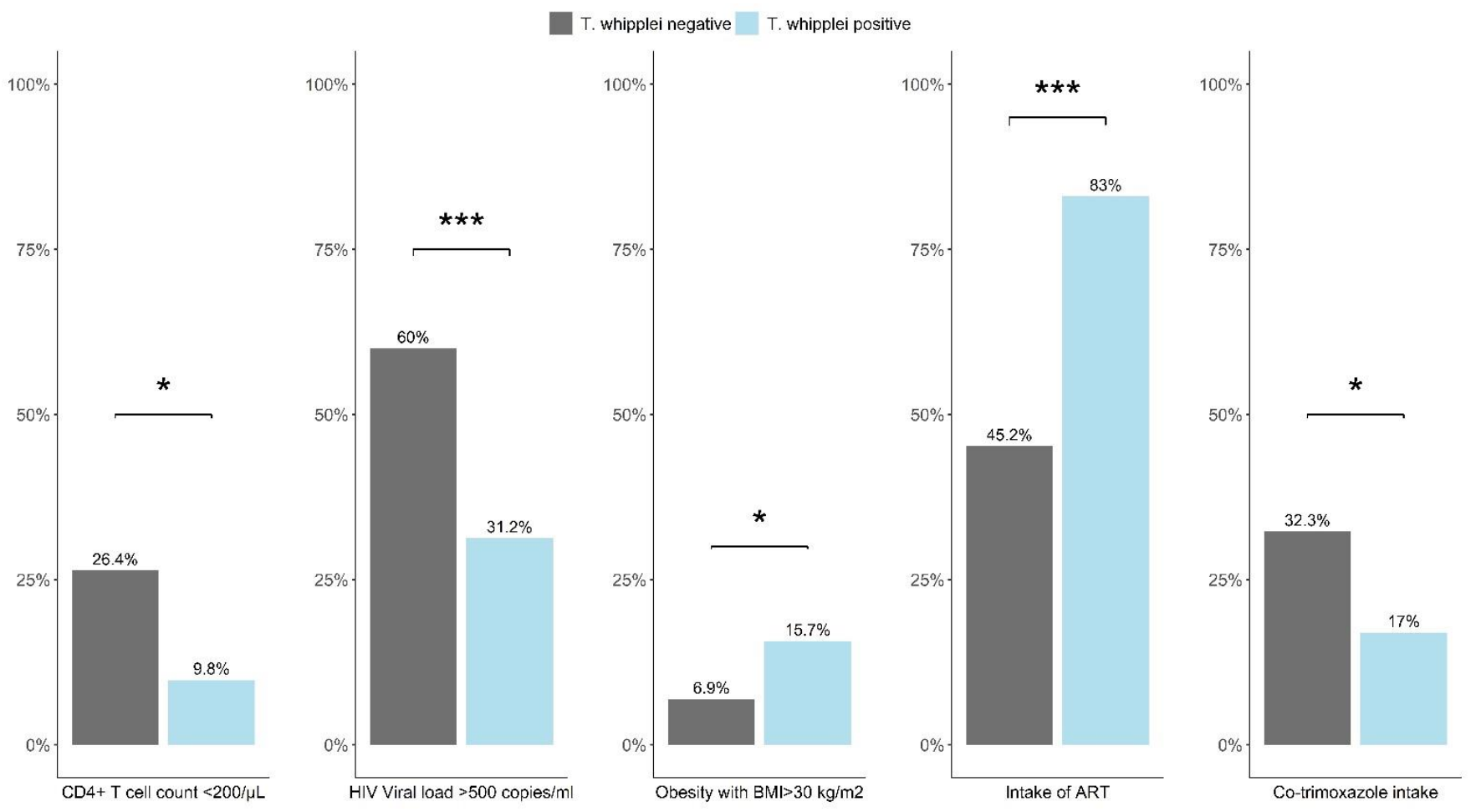

Figure 2. Laboratory, medical, and treatment-related parameters according to T. whipplei status among HIV positive participants. BMI-Body mass index; ART—antiretroviral therapy; ${ }^{*}-p<0.05 ;{ }^{* * *}-p<0.001$.

Table 2. Virological and immunological parameters according to T. whipplei status.

\begin{tabular}{cccc}
\hline Variable & $\begin{array}{c}\text { HIV Positive } \\
\text { T. whipplei Negative, } \\
\text { Median (IQR) }\end{array}$ & $\begin{array}{c}\text { HIV Positive } \\
\text { T. whipplei Positive, } \\
\text { Median (IQR) }\end{array}$ & $p$-Value \\
\hline Viral load, log10 copies/ml & $4.0(1.6-5.3)$ & $1.6(0.0-3.3)$ & $<0.001$ \\
CD4+ T-cell count/ $\mu \mathrm{L}$ & $396.0(184.0-632.5)$ & $525.0(371.0-654.5)$ & 0.007 \\
CD8+ T-cell count/ $\mu \mathrm{L}$ & $960.0(637.0-1381.0)$ & $1034.0(588.5-1220.0)$ & 0.763 \\
CD4+/CD8+ T-cell ratio & $0.4(0.2-0.7)$ & $0.5(0.4-0.8)$ & 0.020 \\
HLA-DR+CD38+CD4+ (\%) & $18.4(10.4-32.8)$ & $11.2(7.3-19.7)$ & 0.009 \\
HLA-DR+CD38+CD8+ (\%) & $42.3(27.5-55.7)$ & $29.1(22.7-40.5)$ & 0.006 \\
CD57+CD4+ (\%) & $16.4(9.4-27.6)$ & $13.9(9.8-26.2)$ & 0.788 \\
CD57+CD8+ (\%) & $49.0(38.9-60.3)$ & $54.6(44.8-68.5)$ & 0.046 \\
PD-1+CD4+ (\%) & $34.5(23.8-49.5)$ & $32.8(22.3-46.3)$ & 0.602 \\
PD-1+CD8+ (\%) & $31.6(19.9-43.6)$ & $20.7(14.9-40.3)$ & 0.074 \\
Ki67+CD4+ (\%) & $13.0(6.9-27.2)$ & $9.3(7.9-11.6)$ & 0.076 \\
Ki67+CD8+ $\%)$ & $10.2(6.0-17.5)$ & $8.4(6.2-16.8)$ & 0.834 \\
\hline
\end{tabular}

IQR-Interquartile range.

In order to determine if virological and immunological parameters were independently associated with the presence of T. whipplei, we adjusted for the intake of co-trimoxazole, sex, and age in individual multivariate logistic regression models. Figure 3 demonstrates that both an HIV viral load below 500 copies/mL as well as a CD4+ T cell count above 200 cells $/ \mu \mathrm{L}$ were associated with a detection of T. whipplei in stool samples, independently from the intake of co-trimoxazole (3.41 OR [1.83-6.64, 95\%CI], and 3.28 OR [1.40-9.61, $95 \% \mathrm{CI}]$, respectively). The third model presented indicates that obesity, defined as a BMI above $30 \mathrm{~kg} / \mathrm{m}^{2}$, also is correlated with a higher probability of T. whipplei carriage (2.34 OR [0.97-5.07, 95\%CI]). Since viral load, CD4+ T cell count, and body weight are affected by the intake and effectiveness of antiretroviral treatment, we added a fourth model demonstrating that ART treatment independently correlates with the presence of 
T. whipplei in stool samples after correction for co-trimoxazole and demographic parameters (6.20 OR [3.10-13.84, 95\% CI]). An alternative interactive logistic regression model revealed no significant interaction effect between co-trimoxazole and ART intake.

Model 1: Dependent variable: Detection of T. whipplei in stool

\begin{tabular}{|c|c|c|c|c|c|}
\hline Variable & & $\mathrm{N}$ & Odds ratio & & $\mathbf{p}$ \\
\hline Age & & 809 & & $0.97(0.94,1.00)$ & 0.09 \\
\hline \multirow[t]{2}{*}{ Sex } & female & 614 & & Reference & \\
\hline & male & 195 & $\longmapsto$ & $1.14(0.51,2.34)$ & 0.74 \\
\hline \multirow[t]{2}{*}{ Cotrimoxazole } & no & 554 & & Reference & \\
\hline & yes & 255 & -1 & $0.50(0.22,1.01)$ & 0.07 \\
\hline \multirow[t]{2}{*}{ HIV_viral_load } & $>500$ copies $/ \mathrm{ml}$ & 467 & 1 & Reference & \\
\hline & $<500$ copies $/ \mathrm{ml}$ & 342 & - & $3.41(1.83,6.64)$ & $<0.001$ \\
\hline
\end{tabular}

Model 2: Dependent variable: Detection of T. whipplei in stool

\begin{tabular}{|c|c|c|c|c|c|}
\hline Variable & & $\mathbf{N}$ & Odds ratio & & $\mathrm{p}$ \\
\hline Age & & 864 & & $0.97(0.94,1.00)$ & 0.08 \\
\hline \multirow[t]{2}{*}{ Sex } & female & 657 & & Reference & \\
\hline & male & 207 & $\longrightarrow$ & $1.16(0.54,2.31)$ & 0.68 \\
\hline \multirow[t]{2}{*}{ Cotrimoxazole } & no & 590 & & Reference & \\
\hline & yes & 274 & & $0.46(0.21,0.92)$ & 0.04 \\
\hline \multirow[t]{2}{*}{ CD4_Tcell_count } & $<200 \mathrm{cells} / \mu \mathrm{l}$ & 219 & & Reference & \\
\hline & $>200 \mathrm{cells} / \mu \mathrm{l}$ & 645 & - & $3.28(1.40,9.61)$ & 0.01 \\
\hline
\end{tabular}

Model 3: Dependent variable: Detection of T. whipplei in stool

\begin{tabular}{|c|c|c|c|c|c|}
\hline Variable & & $\mathrm{N}$ & Odds ratio & & $\mathrm{p}$ \\
\hline Age & & 866 & & $0.98(0.95,1.01)$ & 0.20 \\
\hline \multirow[t]{2}{*}{ Sex } & female & 655 & & Reference & \\
\hline & male & 211 & 一 & $0.93(0.42,1.88)$ & 0.84 \\
\hline \multirow[t]{2}{*}{ Cotrimoxazole } & no & 594 & & Reference & \\
\hline & yes & 272 & & $0.47(0.21,0.93)$ & 0.04 \\
\hline \multirow[t]{2}{*}{ Obesity } & no & 802 & & Reference & \\
\hline & yes & 64 & & $2.34(0.97,5.07)$ & 0.04 \\
\hline
\end{tabular}

Model 4: Dependent variable: Detection of T. whipplei in stool

\begin{tabular}{|c|c|c|c|c|c|}
\hline Variable & & $\mathbf{N}$ & Odds ratio & & $\mathbf{p}$ \\
\hline Age & & 892 & & $0.97(0.94,1.00)$ & 0.06 \\
\hline \multirow[t]{2}{*}{ Sex } & female & 676 & & Reference & \\
\hline & male & 216 & 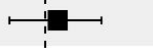 & $1.22(0.57,2.46)$ & 0.59 \\
\hline \multirow[t]{2}{*}{ Cotrimoxazole } & no & 612 & & Reference & \\
\hline & yes & 280 & & $0.43(0.19,0.86)$ & 0.02 \\
\hline \multirow[t]{2}{*}{ ART } & no & 465 & & Reference & \\
\hline & yes & 427 & $\longmapsto$ & $6.20(3.10,13.84)$ & $<0.001$ \\
\hline
\end{tabular}

Figure 3. Factors associated with T. whipplei carriage in HIV positive participants. Multiple logistic regression models displaying odds ratios (95\% confidence intervals) and adjusted $p$-values of independent variables. Obesity defined as $\mathrm{BMI}>30 \mathrm{~kg} / \mathrm{m}^{2}$. ART-antiretroviral therapy. 


\section{Discussion}

To the best of our knowledge, this is the first study investigating the prevalence, risk factors, clinical relevance, and immunological implications of intestinal T. whipplei colonization in a large cohort of HIV positive individuals in Sub-Saharan Africa and one of only few studies on T. whipplei in HIV infected subjects in general.

The prevalence of $T$. whipplei found in our study population was lower than in other studies from Sub-Saharan Africa [5-7]. One cause might be that we included only adult subjects and the majority of those were female $(>75 \%)$, with both characteristics being associated with lower rates of T. whipplei carriage [6,8]. Another aspect is that the cohort studied in our work was recruited at the center of Kumasi, Ghana, a city of 3.3 million inhabitants. The finding that more than half of the participants indicated to have access to tap water and almost all had electricity available within their households suggests that risk factors for acquiring T. whipplei in urban areas might differ from those in rural settings.

In agreement with a study on PLHIV in Europe, there was no accumulation of acute or chronic symptoms in subjects carrying T. whipplei in our cohort from Sub-Saharan Africa [15]. Likewise, Qin et al. reported no impairment of pulmonary function in PLHIV with T. whipplei positive bronchoalveolar lavage samples [14]. Our findings are also in line with a recent work from Ghana in which T. whipplei was found equally in symptomatic pediatric cases and controls [25]. Despite earlier research indicating that individuals might develop mild diarrhea when infected, Feurle et al. concluded in their study of symptomatic patients from different origins that $T$. whipplei was associated with the presence of other stool pathogens, but that an independent causative role of this sole microbe in diarrhea appeared unlikely [26-28].

Co-trimoxazole is recognized for its activity against $T$. whipplei [1]. Since more than $30 \%$ of our HIV positive study population was receiving co-trimoxazole as long-term prophylaxis with a subsequent reduced colonization rate $(7.18 \%$ vs. $3.21 \%, p=0.021)$, we adjusted for the intake of co-trimoxazole in further multivariate models.

In line with earlier studies, the prevalence of T. whipplei was higher in ART-treated HIV positive subjects than in the HIV negative control group $[15,16]$. While Lozupone et al. were not able to detect differences in T. whipplei rates between ART-treated and ART-naïve individuals, possibly due to small sample sizes, we found this pathogen to be significantly more prevalent in patients receiving ART $(10.26 \%$ vs. $1.89 \%, p<0.001)$ [16]. Also, after adjustment for confounders, a high CD4+ T cell count and low HIV-1 viral load as indicators of an effective ART treatment remained significantly associated with a positive T. whipplei status, independent from co-trimoxazole prophylaxis. In addition to this, markers of immune activation were found to be decreased in T. whipplei carriers in our cohort. This finding is in agreement with a study on T. whipplei colonization of the lung in PLHIV, where T. whipplei positivity was not associated with increased systemic or local inflammation [14]. Indeed, Moos and Schneider related an absence of an inflammatory response against $T$. whipplei to the establishment of a chronic infection, which might in part explain the higher prevalence in individuals receiving anti-inflammatory antiretroviral therapy [29]. Obesity was also observed more often in T. whipplei positive compared to negative participants $(12.31 \%$ vs. $5.28 \%, p=0.046)$. Weight loss is a common finding in advanced HIV disease, and an increase in BMI after initiation of first line ART has been described [30]. A similar observation of increased T. whipplei prevalence rates in HIV positive subjects with MetS was made by Garcia-Alvarez et al. [15].

The underlying mechanisms for the observed association of ART intake and parameters indicating efficacy of ART, in particular a low HIV viral load and a high CD4+ cell count, are not obvious. Interestingly, authors of a longitudinal observation of $29 \mathrm{HIV}$ positive subjects found that ART initiation resulted in a decrease of the relative abundance of T. whipplei within individuals, which in a way contrasts our result of lower T. whipplei rates in ART-naïve subjects and associations of favorable immune parameters with T. whipplei carriage [16]. However, Lozupone et al. were testing respiratory specimen for the presence of T. whipplei in that study, whereas we investigated stool samples. Although a longitudinal 
study in a cohort of healthy subjects suggested that individuals with T. whipplei in the lung were also likely to have this identical microbe detected in the stomach, it might be presumed that immunologic control is differently affected by HIV (and related treatment) in the respiratory and gastrointestinal tract [17].

One limitation of our study is that we did not record dynamics of immune parameters (e.g., lowest individual CD4+ T cell counts), or the duration of co-trimoxazole prophylaxis. A severely impaired immune status is associated with more frequent infections, clinical complaints, and thus use of antibiotics, with the possible effect of inadvertent T. whipplei eradication. Furthermore, there is likely a correlation between the immune status at the time of ART initiation and the administration of co-trimoxazole prophylaxis, which cannot be further explored due to this data gap. Other limitations to mention include the fact that we only screened for T. whipplei in stool samples. Although an earlier study by Qin et al. found that multi-site colonization in healthy subjects was common, it would be interesting to investigate if this could be different in advanced HIV disease and if T. whipplei is replaced or overgrown by other bacteria in the gastrointestinal, but not in the respiratory tract. A recent evaluation determined the PCR applied in our study to be of high quality (85\%), but due to different methods used for the detection of T. whipplei, results have to be compared across studies with caution [12]. Because of the cross-sectional design of our study, causal inferences cannot be drawn. A longitudinal study could contribute to the controversial discussion on the impact of HIV disease progression and reversal of immunodeficiency by ART on the prevalence and clinical effects of T. whipplei in PLHIV in Africa.

In conclusion, T. whipplei colonization was more common in this large cohort of HIV infected individuals in West Africa, compared to HIV negative individuals, but not associated with clinical consequences. Among HIV positive individuals, the intake of ART and not being on co-trimoxazole prophylaxis were strongly associated with T. whipplei colonization. Our data suggest that the withdrawal of co-trimoxazole chemoprophylaxis among people living with HIV on stable cART regimen may inadvertently increase the propensity towards colonization with T. whipplei. Longitudinal studies are needed to investigate causality and underlying mechanisms.

Supplementary Materials: The following are available online at https:/ /www.mdpi.com/article/10 $.3390 /$ microorganisms 9081781 /s1, STROBE Statement-Checklist of items that should be included in reports of cross-sectional studies.

Author Contributions: T.F., F.S.S. and K.A.E. designed the study. K.A.E., F.S.S. and B.N. collected samples and clinical data. E.-M.K., V.D.C., A.D., E.O.K. and R.B. performed the experiments. K.A.E. and T.F. analyzed and interpreted the data. K.A.E. and T.F. drafted the manuscript. F.S.S., M.A., B.N., R.O.P. and E.O.K. read and revised the manuscript. All authors have read and agreed to the published version of the manuscript.

Funding: The present study was supported by the ESTHER Alliance for Global Health Partnerships and the German Federal Ministry of Education and Research (Project No. 01KA1102). The publication of this article was funded by the Open Access Fund of the Leibniz Association.

Institutional Review Board Statement: The study was conducted in accordance with the Declaration of Helsinki, and samples were collected and analyzed under protocols approved by the Committee on Human Research of the Kwame Nkrumah University of Science and Technology in Kumasi, Ghana: CHRPE/AP/12/11, and the ethics committee of the Medical Council in Hamburg, Germany: PV3771.

Informed Consent Statement: Informed consent was obtained from all subjects involved in the study.

Data Availability Statement: All relevant data are provided in the manuscript. Raw data can be made available upon reasonable request. Reporting of study methods and results followed the STROBE (Strengthening the Reporting of Observational Studies in Epidemiology Statement) recommendations (Supplementary File). 
Acknowledgments: The authors thank the study participants of the HIV outpatient department as well as the blood bank for their valuable cooperation. They further acknowledge the staff of the Komfo Anokye Teaching Hospital for their enduring work.

Conflicts of Interest: The authors declare that they have no conflicts of interest. The funders had no role in the design of the study, in the collection, analyses, or interpretation of data, in the writing of the manuscript, or in the decision to publish the results.

\section{References}

1. Schneider, T.; Moos, V.; Loddenkemper, C.; Marth, T.; Fenollar, F.; Raoult, D. Whipple's disease: New aspects of pathogenesis and treatment. Lancet Infect. Dis. 2008, 8, 179-190. [CrossRef]

2. Fenollar, F.; Célard, M.; Lagier, J.-C.; Lepidi, H.; Fournier, P.-E.; Raoult, D. Tropheryma whipplei Endocarditis. Emerg. Infect. Dis. 2013, 19, 1721-1730. [CrossRef] [PubMed]

3. Bousbia, S.; Papazian, L.; Auffray, J.P.; Fenollar, F.; Martin, C.; Li, W.; Chiche, L.; La Scola, B.; Raoult, D. Tropheryma whipplei in patients with pneumonia. Emerg. Infect. Dis. 2010, 16, 258-263. [CrossRef]

4. Coria, F.; Cuadrado, N.; Velasco, C.; JJ, J.C.; Jiménez, M.I.; Mena, F.J.; Acebes, J.M. Whipple's disease with isolated central nervous system symptomatology diagnosed by molecular identification of Tropheryma whippelii in peripheral blood. Neurologia 2000, 15, 173-176.

5. Keita, A.K.; Raoult, D.; Fenollar, F. Tropheryma whipplei as a commensal bacterium. Future Microbiol. 2013, 8, 57-71. [CrossRef]

6. Ramharter, M.; Harrison, N.; Bühler, T.; Herold, B.; Lagler, H.; Lötsch, F.; Mombo-Ngoma, G.; Müller, C.; Adegnika, A.A.; Kremsner, P.G.; et al. Prevalence and risk factor assessment of Tropheryma whipplei in a rural community in Gabon: A community-based cross-sectional study. Clin. Microbiol. Infect. 2014, 20, 1189-1194. [CrossRef]

7. Keïta, A.K.; Bassene, H.; Tall, A.; Sokhna, C.; Ratmanov, P.; Trape, J.-F.; Raoult, D.; Fenollar, F. Tropheryma whipplei: A Common Bacterium in Rural Senegal. PLoS Negl. Trop. Dis. 2011, 5, e1403. [CrossRef]

8. Beltrame, A.; Ragusa, A.; Perandin, F.; Formenti, F.; Fenollar, F.; Edouard, S.; Laroche, M.; Zavarise, G.; Doro, F.; Giorli, G.; et al Tropheryma whipplei intestinal colonization in Italian and migrant population: A retrospective observational study. Future Microbiol. 2019, 14, 283-292. [CrossRef]

9. Keita, A.K.; Dubot-Pérès, A.; Phommasone, K.; Sibounheuang, B.; Vongsouvath, M.; Mayxay, M.; Raoult, D.; Newton, P.; Fenollar, F. High Prevalence of Tropheryma whipplei in Lao Kindergarten Children. PLoS Neglected Trop. Dis. 2015, 9, e0003538. [CrossRef] [PubMed]

10. Shams, S.; Rezaei, N.; Beltrame, A.; Moro, L.; Piubelli, C.; Amiri, F.B.; Esmaeili, S. Tropheryma whipplei in Immunocompromised Children in Iran: A Preliminary Study. Preprints 2021, 2021020261. [CrossRef]

11. Fenollar, F.; Trape, J.F.; Bassene, H.; Sokhna, C.; Raoult, D. Tropheryma whipplei in fecal samples from children, Senegal. Emerg. Infect. Dis. 2009, 15, 922-924. [CrossRef] [PubMed]

12. Frickmann, H.; Hanke, M.; Hahn, A.; Schwarz, N.G.; Landt, O.; Moter, A.; Kikhney, J.; Hinz, R.; Rojak, S.; Dekker, D.; et al. Detection of Tropheryma whipplei in stool samples by one commercial and two in-house real-time PCR assays. Trop. Med. Int. Health 2019, 24, 101-108. [CrossRef] [PubMed]

13. Laurens, M.B.; Mungwira, R.G.; Nampota, N.; Nyirenda, O.M.; Divala, T.H.; Kanjala, M.; A Mkandawire, F.; Galileya, L.T.; Nyangulu, W.; Mwinjiwa, E.; et al. Revisiting Co-Trimoxazole Prophylaxis for African Adults in The Era of Antiretroviral Therapy: A Randomized Controlled Clinical Trial. Clin. Infect. Dis. 2021, ciab252. [CrossRef]

14. Qin, S.; Clausen, E.; Nouraie, S.M.; Kingsley, L.; McMahon, D.; Kleerup, E.; Huang, L.; Ghedin, E.; Greenblatt, R.M.; Morris, A. Tropheryma whipplei colonization in HIV-infected individuals is not associated with lung function or inflammation. PLoS ONE 2018, 13, e0205065. [CrossRef] [PubMed]

15. García-Álvarez, L.; Pérez-Matute, P.; Blanco, J.-R.; Ibarra, V.; Oteo, J.A. High prevalence of asymptomatic carriers of Tropheryma whipplei in different populations from the North of Spain. Enferm. Infecc. Microbiol. Clin. 2016, 34, 340-345. [CrossRef] [PubMed]

16. Lozupone, C.; Cota-Gomez, A.; Palmer, B.E.; Linderman, D.J.; Charlson, E.S.; Sodergren, E.; Mitreva, M.; Abubucker, S.; Martin, J.; Yao, G.; et al. Widespread colonization of the lung by Tropheryma whipplei in HIV infection. Am. J. Respir. Crit. Care Med. 2013, 187, 1110-1117. [CrossRef]

17. Qin, S.; Clausen, E.; Lucht, L.; Michael, H.; Beck, J.M.; Curtis, J.L.; Freeman, C.M.; Morris, A. Presence of Tropheryma whipplei in Different Body Sites in a Cohort of Healthy Subjects. Am. J. Respir. Crit. Care Med. 2016, 194, 243-245. [CrossRef] [PubMed]

18. Duro, M.; Manso, M.D.C.; Barreira, S.; Rebelo, I.; Medeiros, R.; Almeida, C. Metabolic syndrome in human immunodeficiency virus-infected patients. Int. J. STD AIDS 2018, 29, 1089-1097. [CrossRef]

19. Sarfo, F.S.; Eberhardt, K.; Dompreh, A.; Kuffour, E.O.; Soltau, M.; Schachscheider, M.; Drexler, J.F.; Eis-Hübinger, A.M.; Häussinger, D.; Oteng-Seifah, E.E.; et al. Helicobacter pylori Infection Is Associated with Higher CD4 T Cell Counts and Lower HIV-1 Viral Loads in ART-Naïve HIV-Positive Patients in Ghana. PLoS ONE 2015, 10, e0143388. [CrossRef]

20. Di Cristanziano, V.; D’Alfonso, R.; Berrilli, F.; Sarfo, F.S.; Santoro, M.; Fabeni, L.; Knops, E.; Heger, E.; Kaiser, R.; Dompreh, A.; et al. Lower prevalence of Blastocystis sp. infections in HIV positive compared to HIV negative adults in Ghana. PLoS ONE 2019, 14, e0221968. 
21. Di Cristanziano, V.; Weimer, K.; Böttcher, S.; Sarfo, F.S.; Dompreh, A.; Cesar, L.-G.; Knops, E.; Heger, E.; Wirtz, M.; Kaiser, R.; et al. Molecular Characterization and Clinical Description of Non-Polio Enteroviruses Detected in Stool Samples from HIV-Positive and HIV-Negative Adults in Ghana. Viruses 2020, 12, 221. [CrossRef]

22. Eberhardt, K.; Sarfo, F.S.; Dompreh, A.; Kuffour, E.O.; Geldmacher, C.; Soltau, M.; Schachscheider, M.; Drexler, J.F.; Eis-Hübinger, A.M.; Häussinger, D.; et al. Helicobacter pylori Coinfection Is Associated with Decreased Markers of Immune Activation in ART-Naive HIV-Positive and in HIV-Negative Individuals in Ghana. Clin. Infect. Dis. 2015, 61, 1615-1623. [CrossRef]

23. Fenollar, F.; Laouira, S.; Lepidi, H.; Rolain, J.-M.; Raoult, D. Value of Tropheryma whipplei Quantitative Polymerase Chain Reaction Assay for the Diagnosis of Whipple Disease: Usefulness of Saliva and Stool Specimens for First-Line Screening. Clin. Infect. Dis. 2008, 47, 659-667. [CrossRef] [PubMed]

24. Vinnemeier, C.; Klupp, E.; Krumkamp, R.; Rolling, T.; Fischer, N.; Owusu-Dabo, E.; Addo, M.; Adu-Sarkodie, Y.; Käsmaier, J.; Aepfelbacher, M.; et al. Tropheryma whipplei in children with diarrhoea in rural Ghana. Clin. Microbiol. Infect. 2016, 22, 65.e1-65.e3. [CrossRef]

25. Heinemann, M.; Strauchs, C.; Lütgehetmann, M.; Aepfelbacher, M.; Klupp, E.-M.; Owusu-Dabo, E.; Rolling, T.; Cramer, J.P.; Vinnemeier, C.D. Polymicrobial enteric infections in African infants with diarrhoea-Results from a longitudinal prospective case-control study. Clin. Microbiol. Infect. 2021. [CrossRef]

26. Lagier, J.-C.; Fenollar, F.; Raoult, D. Acute infections caused by Tropheryma whipplei. Future Microbiol. 2017, 12, 247-254. [CrossRef]

27. Fenollar, F.; Minodier, P.; Boutin, A.; Laporte, R.; Brémond, V.; Noël, G.; Miramont, S.; Richet, H.; Benkouiten, S.; Lagier, J.-C.; et al. Tropheryma whipplei associated with diarrhoea in young children. Clin. Microbiol. Infect. 2016, 22, 869-874. [CrossRef]

28. Feurle, G.E.; Moos, V.; Landt, O.; Corcoran, C.; Reischl, U.; Maiwald, M. Tropheryma whipplei in Feces of Patients with Diarrhea in 3 Locations on Different Continents. Emerg. Infect. Dis. 2021, 27, 932-935. [CrossRef] [PubMed]

29. Moos, V.; Schneider, T. The role of T cells in the pathogenesis of classical Whipple's disease. Expert Rev. Anti-Infect. Ther. 2012, 10, 253-255. [CrossRef] [PubMed]

30. Hasse, B.; Iff, M.; Ledergerber, B.; Calmy, A.; Schmid, P.; Hauser, C.; Cavassini, M.; Bernasconi, E.; Marzolini, C.; Tarr, P.E.; et al. Obesity Trends and Body Mass Index Changes After Starting Antiretroviral Treatment: The Swiss HIV Cohort Study. Open Forum Infect. Dis. 2014, 1, ofu040. [CrossRef] [PubMed] 